\title{
Pattern and Management of Neural Tube Defect in Cameroon
}

\author{
Mathieu Motah ${ }^{1,2}$, Mireille Moumi ${ }^{1,2}$, Aurélien Ndoumbe ${ }^{1,2}$, Clerence Ntieafac ${ }^{1,2}$, \\ Vincent De Paul Djienctheu ${ }^{3,4}$ \\ ${ }^{1}$ Department of Surgery, Faculty of Medicine and pharmaceutical sciences, University of Douala, Douala, Cameroon \\ ${ }^{2}$ Neurosurgical Unit, General Hospital of Douala, Douala, Cameroon \\ ${ }^{3}$ Faculty of Medicine and Biomedical Sciences, University of Yaoundé, Yaounde, Cameroon \\ ${ }^{4}$ Service of Neurosurgery, Central Hospital of Yaoundé, Yaoundé, Cameroon \\ Email:motmath@yahoo.fr, motmath@hotmail.com
}

How to cite this paper: Motah, M., Moumi, M., Ndoumbe, A., Ntieafac, C. and De Paul Djienctheu, V. (2017) Pattern and Management of Neural Tube Defect in Cameroon. Open Journal of Modern Neurosurgery, 7, 87-102.

https://doi.org/10.4236/ojmn.2017.73010

Received: May 31, 2017

Accepted: July 17, 2017

Published: July 20, 2017

Copyright $\odot 2017$ by authors and Scientific Research Publishing Inc. This work is licensed under the Creative Commons Attribution International License (CC BY 4.0).

http://creativecommons.org/licenses/by/4.0/

\begin{abstract}
Objectives: The aim of study was to determine the pattern and management of neural tube defects (NTD). Methodology: It was a hospital based descriptive cross-sectional retrospective study on patients who consulted and/or were admitted at the Douala General hospital for neural tube defects from January 2005 to April 2015. Results: A total of forty-nine (49) patients were enrolled. Males constituted $59.8 \%$ and females $40.2 \%$ giving a sex ratio of 1.5 in favour of males. Most of the parents of the patients (71.5\%) had a low socio-economic status. Myelomeningocele was the most common type (80.4\%) followed by $17.4 \%$ cases of meningocele and $2.2 \%$ cases of lipomeningocele. Three cases (3) of encephaloceles were seen during this period. The commonest site of these defects was the lumbosacral region (47.8\%). Other sites included lumbar $(19 ; 41.3 \%)$, sacral $(3 ; 6.5 \%)$ and thoracolumbar $(2 ; 4.3 \%)$ ones. About half of the patients $(24 ; 48.9 \%)$ presented with ruptured lesions. Hydrocephalus was also recorded in $65.3 \%$ of patients. Talipes equinovarus and talipes calcaneovalgus were the most common associated orthopedic birth defects found. Surgical closure was done for 44 (89.9\%) patients. Ventriculoperitoneal shunting was done in $78.1 \%$ of those who presented with hydrocephalus. Post-operative complications were more frequent in patients with ruptured lesions $(\mathrm{P}=0.001)$. The most common post-operative complications were wound infections (22; 44.9\%) and wound dehiscence (20;40.8\%). Conclusion: Lumbosacral Myelomeningocele was the most common type of NTD in our region. Low socio-economic status was a common risk factor.
\end{abstract}

\section{Keywords}

Neural Tube Defects, Myelomeningocele, Cameroon 


\section{Introduction}

Neural tube defects (NTDs) account for most congenital anomalies of the central nervous system (CNS) and result from failure of the neural tube to close spontaneously between the 3rd and 4th weeks of in utero development. [1] [2].

The prevalence of neural tube defects varies by region, race and ethnicity. Early reports indicated a low prevalence in Africa compared with North America and Europe [3] [4]. Oyewobe et al. [5] reported an incidence of spina bifida (SB) as $0.46 / 1000$ in Nigeria. Recently however, many reports have indicated that the hitherto-held rarity of SB in Africans may no longer be correct. In Nigeria, a high rate of 7/1000 births of NTDs was reported by Airede et al. [6], most (45\%) being myelomeningocele. Outside of Africa, the reported incidence of NTDs per 1000 births varies from 0.2 (in Japan) and 0.8 - 1.4 (in the USA) to 2 - 4 (in the UK) and as high as 6.5 in the Middle East [6]. The management of NTDs requires highly qualified personnel and a significant social cost [7]. Management and supervision of a child and family with a NTD require a multidisciplinary team approach, including surgeons, physicians, and therapists, with one individual (often a pediatrician) acting as the advocate and coordinator of the treatment program. The news that a newborn child has a devastating condition such as myelomeningocele causes parents to feel considerable grief and anger. Prognosis depends on the nature of the defect and ranges from excellent to poor [8].

In Cameroon, the incidence of NTD was $1.99 / 1000$ births in 2008 [9]. A case of tethered cord syndrome (TCS) in an adult was reported in 2014 [10]. We undertook to carry out this study with particular emphasis on the diagnostic and therapeutic aspects to improve on the management of these neural tube defects in our country.

\section{Methodology}

\subsection{Site and Study Period}

It was a hospital based descriptive cross-sectional and retrospective study. The patients were recruited at the neonatalogy and neurosurgical units of the Douala General Hospital (DGH), which is a health care structure at the central level of the Cameroon health system. The study period was ten years (from January 2005 to January 2015).

\subsection{Inclusion Criteria}

All newborns and infants seen with a neural tube defect during the study period at the Douala General hospital, and whose case files were complete.

\subsection{Exclusion Criteria}

All the newborns and infants seen with neural tube defects at the Douala General hospital out of our study period or those seen with incomplete files.

\subsection{Data Collection}

After identifying the patients from the registers (hospitalization registers and 
external consultation registers), their folders (case files) were retrieved from the hospital records department and examined individually by the investigator(s). Data collection was done with the aid of structured forms (questionnaires) designed for the study. The diagnosis of NTD was based on clinical and paraclinical evaluation (as documented by doctors in the patient's case files). Patient's history, including antenatal history, history of exposure to teratogenic drugs (valproic acid, misoprostol, mycophenolate, thalidomide, warfarin, carbamzepin, topiramate, ibuprofen, and captopril) and family history of consanguinity were obtained from the folders. Further information that was obtained from these case files included; maternal age, mode of delivery and the nature and type of NTDs as well as the management (medical and surgical).

\subsection{Medical Treatment}

The newborn or infant with an open NTD were kept warm and the defect was covered with a sterile wet saline dressing. The patient should be positioned in the prone position to prevent pressure on the defect. Oxygen therapy was offered to patients with respiratory distress. Clean intermittent catheterization (CIC) was used in patients with urinary incontinence.

Broad spectrum antibiotics were used to prevent and or treat infections (Meningitis, septicemia, wound infection) in all patients with an open NTD.

\subsection{Surgical Treatment}

The goal of operative repair was to preserve the neural function and prevent infection primarily by obtaining a good skin closure over the defect.

\subsection{Surgical Indications}

1) The newborns or infants with an open NTD had to undergo prompt closure of the defect. The closure involved classic neurosurgical techniques.

2) Children with hydrocephalus also had a ventriculo-peritoneal shunt placed after the NTD closure.

\subsection{Surgical Approach}

Myelomeningocele repair techniques

The Patients were positioned in a prone manner, on the end of a reversed table, so that the surgeon and assistant may sit with adequate leg room. The body was well cushioned at any pressure points (ankles, hips, shoulder and head) with rolled towels. The lesions were cleaned with only normal saline or Ringer lactate solution, taking care to avoid agents that could damage exposed neural tissue.

In an attempt to avoid post-operative complications, the Five-layer closure technique of a MMC was used:

- Isolation and tabulation of the neural placode.

- Reflection and closure of the dural remnant.

- Reflection and closure of the lumbodorsal fascia.

- Deep subcutaneous closure (wide undermining). 
- Skin closure (avoiding edges blanching).

For Visualization of the defect(s) during repair was done with the aid of an operating microscope.

\section{Encephalocele repair techniques}

The position of patient during the surgery depends on localization of encephalocele.

After having made an elliptical skin incision about the base of encephalocele, and dissecting the dural edges from the parenchyma, the remainder of tissue is then amputated carefully. A watertight dural closure is essential, using paricranium or other substitute if necessary. Subsequently, the bony defect must be closed. This most easily facilitated by using the inner table of the skull from an adjacent area. Skin closure, utilizing a subgaleal and cutaneous layer may require trimming excess skin edges for a satisfactory result.

\subsection{Post-Operative Complications}

Immediate post-operative complications such as wound infections, wound dehiscence, meningitis, and CSF leakage as were as long term clinical outcome were noted.

\section{Results}

\subsection{The Total Hospital Delivery at the Study Period Was 10,776 of Which 49 Had NTD Giving an Incidence of 4.5/1000 Births}

Out of the 49 cases of NTD enrolled, there were 29 (59.2\%) males and 20 (48.8\%) females with a male-to-female ratio of 1.5:1. The annual frequency of neural tube defects in our series was 4.9 cases per year. Thirty-two $(65.3 \%)$ of our patients presented at the first week of life while 7 (14.3\%), and $7(14.3 \%)$ of them presented at the second and fourth weeks of life respectively. The 3 (6.1\%) others presented at the third week of life.

Risk factors associated to NTD in our series such as maternal age, socio-economic status, and folic acid supplementation as well as clinical characteristics of the lesions are represented in Table 1.

Seven (14.3\%) mothers gave a history of ingestion of various traditional potions, alcohol and others substances such as "kaolin" during the critical period. None of them reported ingestion of anti-epileptics throughout their pregnancy. In addition, we found that the $3^{\text {rd }}$ birth rank was the most common rank affected $(15 ; 30.6 \%)$. This was closely followed by the $2^{\text {nd }}$ birth rank $(14 ; 28.6 \%)$ and the $4^{\text {th }}$ birth rank $(10 ; 20.4 \%)$ respectively.

\subsection{Maternal Hyperthermia during Pregnancy}

Twelve (25\%) mothers reported that they had fever during the first trimester while the rest $(36 ; 75 \%)$ did not report any notion of fever during this critical period. The exact causes of this fever were not documented in the patients' folders though most of them were treated as malaria. 
Table 1. Risk factors and clinical characteristics.

\begin{tabular}{|c|c|c|}
\hline Variables & Frequency & Percentage (\%) \\
\hline \multicolumn{3}{|l|}{ Maternal age (years) } \\
\hline$>40$ & 4 & 8.2 \\
\hline $30-40$ & 25 & 51.1 \\
\hline $20-30$ & 17 & 34.6 \\
\hline$<20$ & 3 & 6.1 \\
\hline \multicolumn{3}{|l|}{ Maternal acid supplementation } \\
\hline Before pregnancy & 00 & 00 \\
\hline During pregnancy & 44 & 89.1 \\
\hline \multicolumn{3}{|l|}{ Maternanl socio-economic status } \\
\hline Lower class & 35 & 71.4 \\
\hline Middle class & 10 & 20.4 \\
\hline Upper class & 4 & 8.2 \\
\hline \multicolumn{3}{|l|}{ Type of encephalocele } \\
\hline Meningocele & 1 & 33.3 \\
\hline Meningo encephalocele & 2 & 66.7 \\
\hline \multicolumn{3}{|l|}{ Type of spina bifida } \\
\hline Meningoce & 8 & 17.5 \\
\hline Myeomeningocele & 37 & 80.3 \\
\hline lipomeningocele & 1 & 2.2 \\
\hline \multicolumn{3}{|l|}{ Nature of spina bifida } \\
\hline Ruptured & 24 & 52.2 \\
\hline Un ruptured & 22 & 47.8 \\
\hline \multicolumn{3}{|l|}{ Site of lesion } \\
\hline Thoraco lumbar & 2 & 4.3 \\
\hline Lumbar & 19 & 41.3 \\
\hline Lumbo sacral & 22 & 47.8 \\
\hline sacral & 3 & 6.6 \\
\hline \multicolumn{3}{|l|}{ Size of lesion } \\
\hline Greater than $15 \mathrm{~cm}$ & 1 & 2.1 \\
\hline $10-15 \mathrm{~cm}$ & 15 & 30.5 \\
\hline $5-10 \mathrm{~cm}$ & 31 & 63.1 \\
\hline Less than $5 \mathrm{~cm}$ & 2 & 4.3 \\
\hline \multicolumn{3}{|l|}{ Associated neurological deficit } \\
\hline Urinary and fecal deficit & 30 & 61.2 \\
\hline Lower limb motor an sensory deficit & 32 & 65.3 \\
\hline
\end{tabular}

\subsection{Personal and Family History of Neural Tube Defects}

One (2.04\%) patient in our series had a family history of spina bifida (in her aunty).

The prenatal diagnosis of the various NTDs seen in our sample was made in only $6(12.2 \%)$ cases, all of them during the third trimester with the aid of obstetric ultrasound.

\subsection{Birth Defects Associated to the NTDs}

Hydrocephalus was seen in 32(65.3\%) cases. Talipesequinovarus and talipescalcaneovalgus were the most common associated orthopedic birth defects seen; congenital heart disease and bilateral undescended testes were seen in some cases, as shown in Table 2. 
Table 2. Associated birth defects.

\begin{tabular}{ccc}
\hline Variables & Frequency & Percentage \\
\hline Hydrocephalus & 32 & 65.3 \\
Bilateral talipes calcaneovalgus & 9 & 18.4 \\
Bilateral talipes equinovarus & 8 & 16.3 \\
Unilateral talipes calcaneovalgus & 2 & 4.1 \\
Unilateral talipes equinovarus & 2 & 4.1 \\
Overriding toes & 2 & 4.1 \\
Genu recurvatum & 2 & 4.1 \\
Congenital hip dislocation & 1 & 2.0 \\
Congenital heart disease (ventricular septal defects) & 3 & 6.1 \\
Bilateral undescended testes & 2 & 4.1 \\
No abnormality & 15 & 30.6 \\
\hline
\end{tabular}

\subsection{Imaging Studies}

Brain CT-Scans were done in all the thirty-two (32) cases of hydrocephalus. The hydrocephalus was triventricular in $82.37 \%$ of cases, tetra ventricular in $14.42 \%$ of cases and biventricular in $3.21 \%$ of cases.

\subsection{Primary Outcome Measures of the Patients}

Forty-one $(83.7 \%)$ of the 49 patients in our study population were discharged after surgical repaired of their lesions. Two (4.1\%) of them were discharged against medical advice while three others $(6.0 \%)$ died before surgery.

\subsection{Medical Approach}

Out of the $41(83.7 \%)$ patients who were discharged after surgical treatment, all of them were offered medical treatment (antibiotics, analgesic)

\subsection{Surgical Approaches}

Forty-four (89.8\%) patients had their defects closed at birth, 25 (70\%) of them within the first 48 - 72 hours following admission. The 16 (39\%) others were operated after the fourth day of admission. Out the 32 (65.3\%) patients who had hydrocephalus, ventriculoperitoneal shunting was performed in 25 (78.1\%) of cases (Table 3). 24 (64.9\%) of those treated for hydrocephalus had myelomeningocele. All these ventriculoperitoneal shunts were placed after definitive repair defects (Figure 1).

\subsection{Evolution and Prognosis Following Treatment}

Twenty-seven (55.1\%) of our patients had complications following surgery, while the $22(44.9 \%)$ others did not have any immediate post-operative complications. The most common post-operative complication was wound infections (22; 44.9\%). Other immediate post-operative complications were wound dehiscence $(20 ; 40.8 \%)$, CSF leakage $(10 ; 20.4 \%)$ and meningitis/sepsis $(16 ; 32.7 \%)$. 
Table 3. Different surgical approaches as per clinical type of lesion.

\begin{tabular}{ccc}
\hline Type of lesion & Simple surgical closure only & Surgical closure associated to VPS \\
\hline myelomeningocele & $13(35.1 \%)$ & $24(64.9 \%)$ \\
meningocele & $7(87.5 \%)$ & $1(12.5 \%)$ \\
encephalocele & $3(100 \%)$ & $0(0 \%)$ \\
lipomeningocele & $1(100 \%)$ & $0(0 \%)$ \\
\hline
\end{tabular}
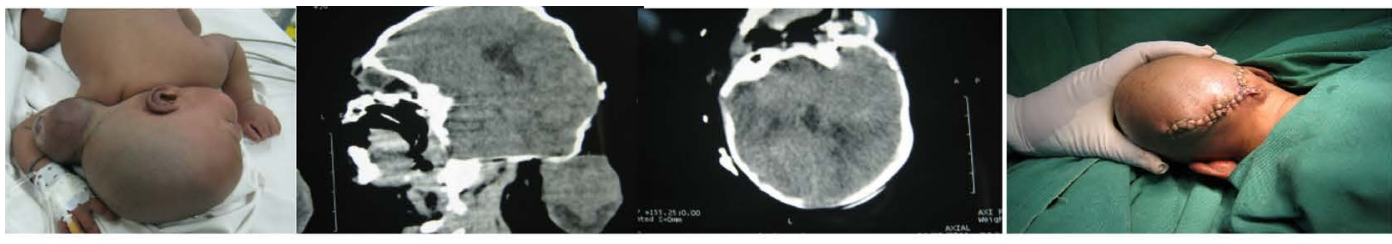

An Occipital encephalocele. Preoperative image, brain CT-scan showing an encephalocele and lambda enlargement of patient and postoperative image.
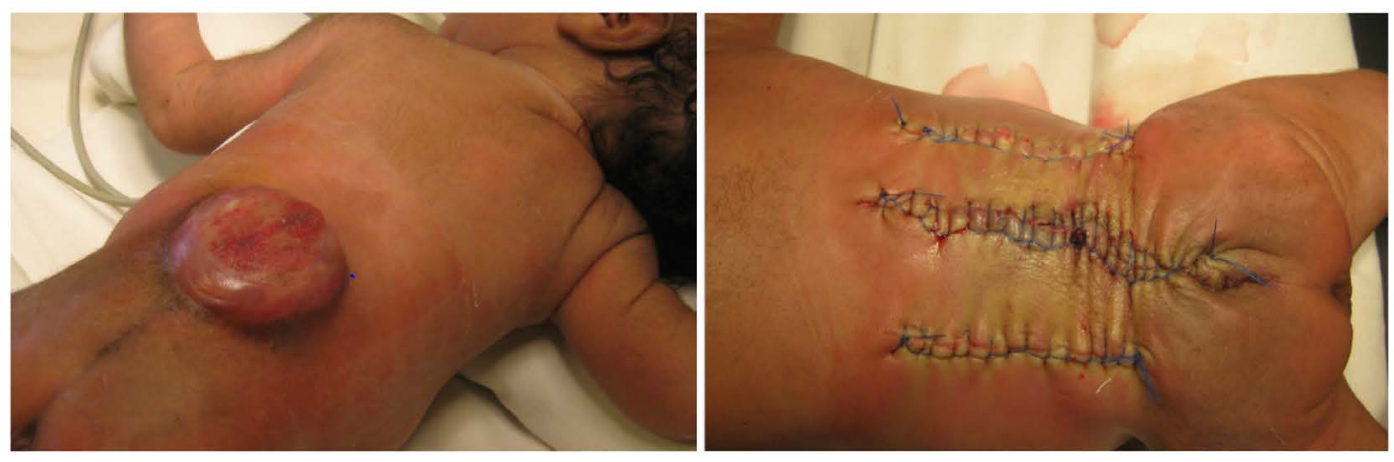

A large lumbar myelomeningocele operated with two lateral incisions to distend the skin.

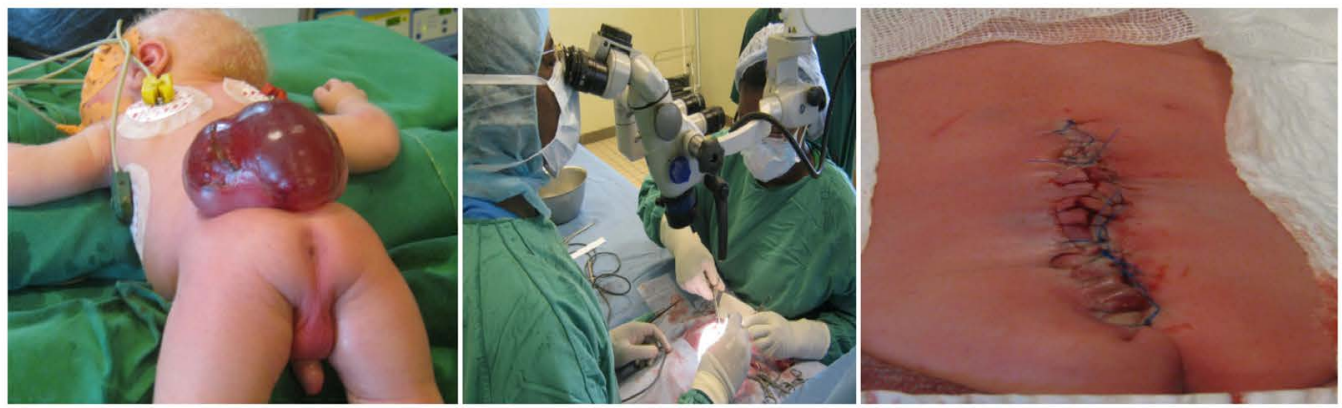

A radiculo meningocele of an albino baby operated using a microscope.

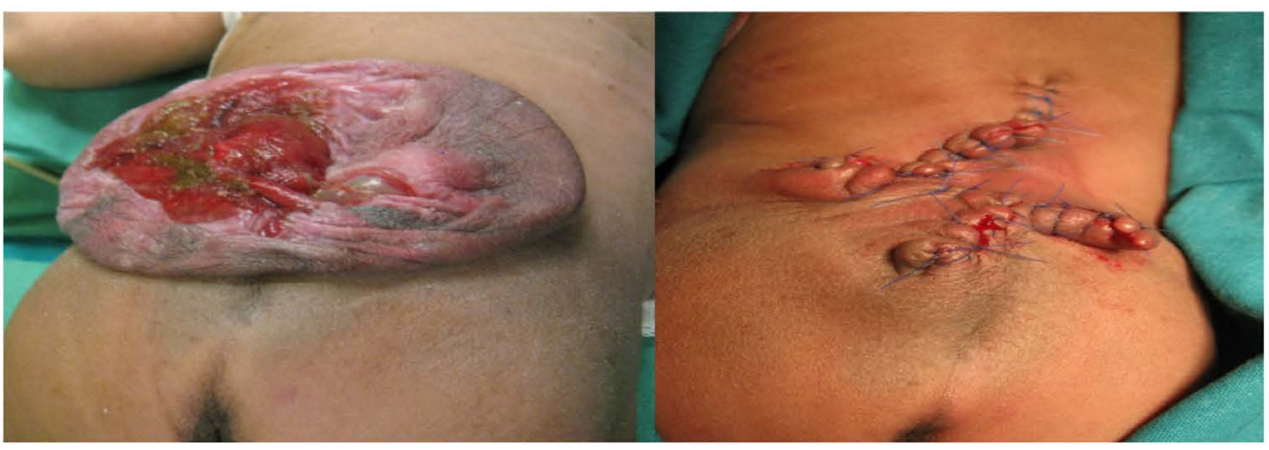

A lumbo-sacral myelo menincocele operated using $\mathrm{H}$ plasty technique for closure of the large defect.

Figure 1. Surgical techniques. 
Three patients died immediately after surgery due to cardio-pulmonary compromise. The overall mortality rate was $12.2 \%$.

\subsection{Factors Affecting Post-Operative Complications}

\subsubsection{Nature of the Lesions (Ruptured or Unruptured)}

Complications observed after surgery were more frequent in patients seen with ruptured lesions at presentation than in those with unruptured lesions. These complications were wound infection, wound dehiscence and meningitis. This was statistically significant; p-value 0.0001 (Table 4).

\subsubsection{Age of the Patients}

Complications seen after surgery were more frequent $(15 ; 46.9 \%)$ in patients seen during the first week of life than in those seen during the second, third and fourth weeks of life This was statistically not significant ( $\mathrm{p}$ value $=0.2523$ ).

\subsubsection{Fetal Birth Weight (FBW)}

Complications after surgery were more frequent in patients with normal birth weight. This was not statistically significant.

\subsubsection{Size of the Lesions}

The occurrence of complications was directly proportionally related to the size of the lesion, although this was not statistically significant.

\subsubsection{Type of the Lesion}

Patients with myelomeningocele suffered from more complications after surgery than those with other type of lesions. This was not statistically significant.

\subsection{Long Term Clinical Outcome of the Patients}

Out of the 41 patients who were discharged after surgery, 16 (39.0\%) of them were completely lost to follow-up a few months to years after discharge from hospital. Ten (24.4\%) of the remaining 25 patients were reported to have died a few months (some a few years) after surgery. Most of them were said to have presented symptoms of progressive hydrocephalus (enlarging cranium, sun-setting appearance of the eyes, vomiting, dilated scalp veins). The remaining 15 (36.6\%) are reported to be alive with a majority of them $(12 ; 80.0 \%)$ having gross motor and sensory deficits as well as bi-sphincteric dysfunction. The three others (20.0\%) have completely recovered. Eleven $(91.7 \%)$ of those who are alive with gross motor and sensory deficits as well as bi-sphincteric dysfunction presented with myelomeningocele.

Table 4. Comparing the nature of the lesions and complications after surgery.

\begin{tabular}{cccccc}
\hline Nature of the lesions & No complications & Complications & Total & Chi-square & P-value \\
\hline Ruptured & $4(16.7 \%)$ & $20(83.3 \%)$ & 24 & 14.679 & 0.0001 \\
Unruptured & $16(72.7 \%)$ & $6(27.3 \%)$ & 22 & & \\
\hline
\end{tabular}




\section{Discussion}

\subsection{General Characteristics and Socio-Demographic Factors of the Patients}

The main objective of this study was to determine the pattern and management of neural tube defects at the Douala General hospital over a 10 years period from the $1^{\text {st }}$ of January 2005 to the $31^{\text {st }}$ of January 2015. A total of 49 patients were enrolled during this period, giving an annual frequency of 4.9 cases per year. In Niger, Sanoussi S et al. [11] reported 387 cases of neural tube defects (with an annual frequency of 38.7 cases per year) in a descriptive retrospective study over a 10 years period at the Niamey General hospital between 1990 and 2000. Similarly, Ouattara O et al. [12] in Cote D'ivoire reported 132 cases of myelomeningocles (with an annual frequency of 11cases per year) in the pediatric units of the Cocody and Youpougon Universty teaching hospitals.

Kabre et al. [13] in a similar study in Dakar affirmed that "Spina bifida is the third reason for hospitalizations in the pediatric neurosurgical units, after brain/spinal cord injuries and hydrocephalus".

This annual frequency is just an estimate and does not necessary reflect the real frequency of neural tube defects in our region because though the Douala General Hospital is a referral hospital where such pathologies are properly managed, all the cases of neural tube defects in Douala are not managed there. Moreover, some of the patients referred from the other health institutions to this referral hospital for proper management of their babies defects might not have reported to the Douala General Hospital because of the prevailing folk religious belief about the occurrence of spina bifida.

Some see the birth of the child as a punishment from God. Oyewole et al. [5], ound that a third of their clients incriminate witchcraft as the cause of their child's predicament.

Out the 49 patients enrolled, there were 29 (59.2\%) males and 20 (48.8\%) females with a male-to-female ratio of 1.5 in favour of males. Njamnshi KA and his collaborators in a cross-sectional retrospective study at the neonatology unit of the mother and child center-Yaounde in 2008, [9] reported a male predominance $(69.57 \%)$ in their sample. These results are at variance with those obtained by Sanoussi et al. [11], Kabre et al. [13]. They reported a female predominance of $53.74 \%$ and $51.18 \%$ respectively. Literature reports a slight female predominance. In our opinion, these differences may be due to the context since NTDs are said to vary from one region to another.

In our series, a majority of the patients $(32 ; 65.3 \%)$ were seen during their first week of life even though none of them was seen within the first 24 hours of life. Some $(7 ; 14.3 \%)$ were seen only during the fourth week of life. These results are similar to those obtained by Ouattara $\mathrm{O}$ et al. [12]. They reported that none of their patients was seen before the sixth $\left(6^{\text {th }}\right)$ hour of life. As a matter of facts, $53.3 \%$ of their patients were seen only after the first week of life. In Dakar, Kabre et al. [13] came to the conclusion that "a majority of children with NTDs are seen during their first month of life". This late first neurosurgical consultation 
exposes the children to several complications before and after surgery. In our opinion, it might be due to late referral, financial difficulties and sometimes folk cultural and religious beliefs that NTDs are a punishment from God.

\subsection{Risk Factors of Neural Tube Defects in Our Series}

\subsubsection{Socio-Economic Status of Parents}

Thirty-five (71.5\%) parents of the patients were found to have a low socioeconomic status while only 4 (8.2\%) had a high socio-economic status (Table 1 ). Kabre et al. [13] had established that the lesion is common among mothers of low socio-economic status. This is validated by recent studies. Poverty can predispose to deficiency in some essential vitamins [14] [15].

\subsubsection{Folic Acid Supplementation}

It is generally accepted that inadequate intake of natural folate, or its synthetic form folic acid, before and during early pregnancy is associated with increased risk of spina bifida [7] [16] [17]. Evidence is also increasing that low maternal vitamin $B_{12}$ may be associated with an increased risk of the spina lesion [14]. None of the mothers in our series was supplemented for folic acid before pregnancy and most of them who took folic acid did not do so during the critical period. Alatise et al. [7], reported that only 3 mothers in their series took FA before pregnancy. This might have been due to several reasons; late commencement of antenatal care consultation (most patients showed up for ANC for the first time only after the first trimester). Lack of experience, and moreover most of the time, they did not even know they were pregnant during the critical period.

\subsubsection{Birth Ranks of the Patients}

We found that the 3rd birth rank was the most common rank affected. Alatise et al. found that.

Fourth born children were affected more [7]. This was corroborated by work done by Elwood et al. [15]. This may be due to exhaustion of the folate store of the mother with repeated pregnancies. It may be necessary to consider a higher dose of multivitamin supplements in women with higher parity so as to enhance the storage of the vitamin in the body.

\subsubsection{Maternal Age}

The modal age group of the mothers was $30-40$ years $(25 ; 51.2 \%)$ while the mean age of the mothers was $30 \pm 6$ years (Table 1). Kabre et al. [13] found that the modal age group was $26-31$ years with an average age of the mothers was 28 years. The risk of birth defects affected pregnancy increases with maternal age. In fact, neural tube defects are said to be more frequent in parents aged below 19 years and above 40 years [18].

\subsubsection{Clinical Types of Neural Tube Defects}

There were 46 (93.9\%) cases of spina bifida and $3(6.1 \%)$ cases of encephaloceles (Figure 1). No case of anencephaly was found during this period. This rarity of anencephaly as also reported by Njamnshi KA and his collaborators in a cross- 
sectional retrospective study at the neonatology unit of the mother and child center-Yaounde, [9] does not necessarily reflect its true incidence since a large proportion of anencephalic babies are aborted spontaneously or die immediately after birth. Moreover, anencephalic babies born in other health care institutions may not have been referred to the Douala General Hospital for management since it is known that, this particular type of neural tube defect is incompatible with life.

The majority $(37 ; 80.4 \%)$ of patients had myelomeningocele as the clinical type of spina bifida cystica (Table 1). These results are similar to those obtained by Njamnshi et al. [9] who found that MMC represented $68.11 \%$ of cases. Similarly, Alatise et al. [7] in 2006 reported that myelomeningocele was the most common clinical type (86.8\%). Many other authors such as Sanoussi et al. [11], Kabre et al. [13], Uba et al. [3] reported that MMC was the most frequent type of lesion in $63.22 \%, 62.22 \%$ and $79.58 \%$ of cases respectively. Literature reports indicate that myelomeningocele generally represents about $80 \%$ of spina bifida aperta. These proportions of MMC therefore reflect literature reports.

Almost a tenth $(8 ; 17.4 \%)$ of our patients had meningocele (Table 2). Some authors [19] [20] reported a high prevalence of meningocele (70.1\%) while Airede et al. [6] and Uba et al. [3] reported similar results to ours: $14.3 \%$ and $15.5 \%$ of meningocele respectively. Only 1 (2.2\%) case of lipomeningocele was seen during this period (Table 2). Similar results were found by Kabre et al. [13] who reported 3.79\% cases of lipomeningocele.

Three cases of encephaloceles were found during this period, $2(66.7 \%)$ of which were meningo-encephaloceles while one $(33.3 \%)$ was meningocele. This was less compared to the 58 cases of encephaloceles reported by Sanoussi and his collaborators in a 10 years retrospective study at the Niamey hospital [11]. There is variability in the occurrence of Neural tube defects across regions, race and time.

\subsubsection{Site of the Lesions}

The most common site for the lesion was lumbosacral (22; 47.8\%). Other sites include lumbar $(19 ; 41.3 \%)$, sacral $(3 ; 6.5 \%)$ and thoracolumbar $(2 ; 4.3)$. None of the lesions was located in the cervical area (Table 4). These results were similar to those obtained by Alatise and his collaborators [7] at the pediatric surgery and neurosurgical units of Obafemi Awolowo university in Nigeria, who reported that the commonest site of the lesions was lumbosacral (55.7\%). Many other studies [9] [10] reported that lumbosacral MMC was the commonest clinical type of spina bifida aperta. These figures are in agreement with literature reports.

\subsubsection{Nature of the Lesions}

Another finding was that, about half of the patients $(24 ; 52.2 \%)$ had ruptured lesions at presentation while the $22(47 ; 8 \%)$ others were intact and this significantly affected post-operative complications (Table 4). All the babies seen with ruptured lesions were delivered per-vagina (spontaneous vagina delivery/breech) 
while those delivered by elective cesaerian section all had unruptured lesions. This proportion is lower compared to findings in the work done by Ouattara and his collaborators in the pediatric surgery units of the Cocody and Youpougonuniversity hospitals were they found that $71 \%$ of patients had ruptured and ulcerated lesions at presentation [12].

Trauma to the lesions during per-vagina delivery may have contributed to the rupture of the lesions. Moreover, most patients were referred and presented late to the specialized care units were these defects are managed. So, the thin fragile membrane covering the neural placode ruptures before the patients' admission.

\subsection{Associated Neurological Deficits}

Various degrees of neurological deficits were seen in patients with myelomeningocele depending on the level of the lesion (Table 2). 30 (61.2\%) patients in our series had features suggestive of urinary and fecal incontinence at presentation, while $32(65.3 \%)$ of them had lower limb motor and sensory deficits. Kumar R et al. and Alatise et al. [7], had reported similar results. These sphincteric dysfunctions were more frequent in patients with myelomeningocele.

Alatise and his collaborators [7] found that 89 (83.9\%) out of 106 patients presented with motor/sensory lower limb deficits. The proportions reported by Alatise et al. [7], are logically greater than ours because there were more cases of myelomeningoceles in their series. These associated neurological anomalies are largely influenced by the spinal level of the lesion.

Hydrocephalus which was present in $32(65.3 \%)$ of cases was clinically obvious before surgery in most of our patients. This number is high compared to the $40.02 \%$ cases of Hydrocephalus reported by Njamnshi and his collaborators [9] but similar to the $68.3 \%$ cases of hydrocephalus reported by the Uba and his collaborators [3]. This difference may be explained by the fact that most of our patients presented late and already had clinically obvious signs of hydrocephalus, while in the other studies mentioned above, the patients presented much earliar and had their defects closed. They may have started developing clinically obvious signs of hydrocephalus only after discharge.

Talipesequinovarus and calcaneovalgus were the most common associated orthopedic birth defects seen (21 cases); congenital heart disease and bilateral undescended testes ( 3 cases and 2 cases respectively) were seen during this period. Alatise et al. [7] reported similar results in 2006. However, these associated anomalies are not considered to form part of the syndrome of neural tube defect [21] [22].

\subsection{Therapeutic Aspects}

Forty-four (89.8\%) patients had their defects surgically repaired at birth. Out the $32(65.3 \%)$ patients who had hydrocephalus, ventriculo-peritoneal shunts were placed in 25 (78.1\%) patients (Table 3). Twenty-five (70\%) of the 44 (89.8\%) patients who had their defects surgically closed at birth were operated after the first week following admission. The 16 (39\%) others were operated during the first 
week of admission. Ouattara and his collaborators in a study carried out at the pediatric surgery units of the Cocody and Youpougon university hospitals in Cote d'Ivoire [13] reported than $60 \%$ of their patients were operated after the first week of life. There are different surgical techniques of repairing myelomeningocele [20] [23] [24] [25] [26].

This delay in the surgical management of these defects could be due to the inability of most of the parents to meet up with the financial demands necessary for the operations, giving their low socio-economic status. None of the patients in our series benefited from modern treatment (ventriculocisternotomy). Patients seen with associated hydrocephalus had to first undergo simple surgical closure of their lesions with the aid of an operating microscope before benefiting from a ventriculo-peritoneal shunting of their hydrocephalus at a later date.

\subsection{Postoperative Clinical Outcome}

\subsubsection{Immediate Postoperative Complications}

The commonest complication before surgery was cerebro-spinal fluid leakage (22; 47.8\%). This was closely followed by meningitis/sepsis and death before surgery $(3 ; 6.1 \%)$. The presence of these pre-operative complications severely delayed the surgical repair of some patients' defects.

The most frequent post-operative immediate complications were wound infections $(22 ; 48.9 \%)$ and wound dehiscence $(20 ; 40.8 \%)$. Post-operative complications were significantly more common in patients with ruptured lesions (Table 4). These results were corroborated by work done by Alatise et al. [7], Airede et al. [6] and Shehu et al. [20].

All these authors reported that immediate post-operative complications dominated by wound infections and wound dehiscence were significantly more common in patients who presented with ruptured lesions.

This is due to the fact that most of these patients already had signs of infections before admission. In addition, most patients with infections of the sac died of septicemia and meningitis.

Another finding noted in this study is the overall mortality rate of $12.2 \%$ (6 patients). Njamnshi et al. [9] reported a mortality rate of $11.59 \%$ (8 patients), while Alatise et al. [7] reported an overall mortality rate of $22.4 \%$ (24 patients). Most of the patients in our series were referred from peripheral health facilities where supervised delivery cannot be guaranteed. More-over, some of the babies were delivered in mission houses and some at home. Most of the pregnancies and deliveries were not supervised; hence, many of the patients had infections at presentation.

In addition, many presented late because of ignorance and lack of funds. These additional factors are related to the low socio-economic status of the parents. All these may be responsible for the high mortality.

\subsubsection{Short Term Clinical Outcome}

A few months after surgery, 16 (39.0\%) were lost to follow-up. Only $15(36.6 \%)$ could be account for while the $10(24.4 \%)$ others were reported to have died. 
This situation was equally reported by Kabre et al. [13] in Senegal and Sanoussi et al. [11] in Niger where $45.67 \%$ and $66.49 \%$ of the patients operated respectively were lost to follow up after surgery. This makes it difficult for us to appreciate the long term prognosis of our patients. Financial constraints and to some extent folk religious and cultural believes were responsible for such observations. Some of the Patients unaccounted for might have died thus increasing the overall mortality.

\subsubsection{Prevention of Neural Tube Defects}

Apart from socio-cultural factors such as early motherhood, consanguineous marriage and low socio-economic status, we can also mention teratogenic drugs that should not be used during pregnancy. Gestational diabetes is also a risk factor has proved [16] [17] [18] [27]. Prenatal management of NTD in Cameroon is limited to diagnostic obstetrical ultrasounds.

\section{Conclusions}

Neural tube defects (NTDs) are a serious disabling but preventable congenital malformation, with an annual frequency of 4.9 cases/year at the DGH. There was a male predominance (59.2\%) in our sample. A majority of our patients (71.5\%) were born of parents with a low socio-economic status.

Lumbo-sacral MMC was the most frequent (80.4\%) clinical type of the lesions. Lower limbs paralysis and paresis (61.2\%) as well as bi-sphincteric dysfunctions (65.3\%) were equally very common especially in patients with lumbar and lumbo-sacral MMC. About half of the patients (52.2\%) presented with ruptured lesions and this significantly affected post-operative complications. Hydrocephalus was seen in $32(65.3 \%)$ cases. Talipesequinovarus and talipescalcaneovalgus were the most common associated orthopedic birth defects seen.

Prenatal management and outcome at birth in our series were limited by poverty and folk cultural and religious beliefs. The treatment of other associated birth defects notably orthopedic defects and urinary incontinence is poorly developed in our milieu.

The overall mortality rate was relatively high in our series (12.3\%). Late referral, financial constraints and the presence of complications before surgery significantly contributed to this high.

\section{Recommendations}

\section{In the light of the above mentioned results, we formulate the following} recommendations:

1. Educate the public on the risk factors of NTDs.

2. Subsidize and encourage the systematic supplementation of women of child bearing ages with folic acid during the periconception period.

3. Envisage adopting mandatory fortification of flour and other food stuff with folic acid as recommended by the World Health Organization.

4. Reduce the cost of treatment of NTDs in this reference hospital so that every 
child born with a NTD could be offered adequate treatment.

5. Involve other specialists (Urologists, pediatricians, physicians, physiotherapists) in the management of children born with NTDs.

6. Ensure early referral of babies born with NTDs in aseptic and non-traumatic conditions to specialized health centers for proper and timely management.

7. Advise women trying to conceive to take a dose of $400 \mu \mathrm{g}$ folic acid daily, starting two months before the planned pregnancy and to continue until they are 12 weeks pregnant.

8. Counsel pregnant women who have previously had a baby with NTD or who have diabetes or who are under anticonvulsant treatment about the increased risk of a future baby being affected and advise them to take $5 \mathrm{mg}$ folic acid daily and increase their food intake of folate.

9. We strongly recommend prospective studies on this malformation with a close fellow up of patients.

\section{References}

[1] Stoll, B.G. (2008) Congenital Anomalies. In: Kliegman, R.M., Jenson, H.B., Behrnan, R.E. and Staton, B.F., Eds., Nelson Textbook of Pediatrics, 18th Edition, WB Sanders Co, 711-713.

[2] Haslam, R.H.A. (2000) Congenital Anomalies of the Central Nervous System. In: Behrman, R.E., Kliegman, R.M. and Jenso, H.B., Eds., Nelson Textbook of Paediatrics, 16th Edition, Saunders, Philadelphia, 1803-1810.

[3] Uba, A.F., Isamade, E.S., Chirdan, L.B., Edino, S.T. and Igun, G.O. (2004) Epidemiology of Neural Tube Defects in North Central Nigeria. African Journal of Paediatric Surgery, 1, 16-19.

[4] Shanta, K., Rajalaxmi, P. and Sadananda, R. (2014) Neurl Tube Defect: Epidemiologic and Demographic Implication. IOSR Journal of Dental and Medical Sciences (IOSR-JDMS), 13, 1-4.

[5] Oyewole, A., Adeloye, A. and Adeyokunnu, A.A. (1985) Psychosocial and Cultural Factors Associated with the Management of Spina Bifida Cystica in Nigeria. Developmental Medicine \& Child Neurology, 27, 498-503. https://doi.org/10.1111/j.1469-8749.1985.tb04574.x

[6] Airede, K.I. (1992) Neural Tube Defects in the Middle Belt of Nigeria. Journal of Tropical Pediatrics, 38, 27-30. https://doi.org/10.1093/tropej/38.1.27

[7] Alatise, O.I., Adeolu, A.A., Komolafe, E.O., Adejuyigbe, O. and Sowande, A. (2006) Pattern and Factors Affecting Management Outcome of Spina Bifida Cystic in IleIfe, Nigeria. Pediatric Neurosurgery, 42, 277-283. https://doi.org/10.1159/000094062

[8] Ambe, J.P., Nadziga, A.G., Akpede, G.O. and Mava, Y. (2010) Pattern and Outcome of Congenital Abnormality in Newborn Babies in a Nigerian Teaching Hospital. West Africa Medicine, 29, 24-29.

[9] Djientcheu, V.D.P., Njamnshi, A.K., Wonkam, A., et al. (2008) Management of Neural Tube Defects in a Sub-Saharan African Country: The Situation in YaoundéCameroon. Journal of the Neurological Sciences, 275, 29-32. https://doi.org/10.1016/j.jns.2008.07.003

[10] Motah, M., Felix, U., Ndoumbe, A., Moumi, M.G. and Djientcheu, V.D.P. (2014) Tethered Cord Syndrome in Adults: A Case Report in Cameroon. The Pan African Medical Journal, 17, 217. https://doi.org/10.11604/pamj.2014.17.217.3516 
[11] Sanoussi, S., Gamatie, Y., Kelani, A., et al. (2001) Malformations du tube neural au Niger: A propos de 387 cas en 10 ans: Plaidoyer pour un traitement préventif par l'acide folique en période périconceptionnelle. Médecine d'Afrique noire, 48, 509515.

[12] Ouattara, O., Dieth, A., Kouame, B., et al. (1997) Les myelomeningoceles en Afrique: Cas de la Cote D'ivoire. Médecined'Afrique Noire, 44.

[13] Kabre, A., Badiane, S.B., Sakho, V., Ba, M.C. and Gueye, M. (1994) Genetic and Etiologic Aspects of Spina Bifida in Senegal: Apropos of Zil Cases Collected at the Neurosurgical Clinic UHC of Fann. Dakar Medical, 39, 113-119.

[14] Antony, A.C. (2003) Vegetarianism and Vitamin $B_{12}$ (Cobalamin) Deficiency (Editorial). The American Journal of Clinical Nutrition, 78, 3-6.

[15] Elwood, J.M., Little, J. and Elwood, J.H. (1992) Epidemiology and Control of Neural Tube Defects. Oxford University Press, New York.

[16] Castillo-Lancelloti, C., Tur, J.A. and Uau, Y.R. (2013) Impact of Folic Acid Fortification of Flour on Neural Tube Defects. Public Health Nutrition, 16, 901-911.

[17] Yerby, M.S. (2003) Management Issues for Women with Epilepsy: Neural Tube Defects and Folic Acid Supplementation. Neurology, 61, S23-S26. https://doi.org/10.1212/WNL.61.6_suppl_2.S23

[18] Fieggen, K. and Stewart, C. (2014) Aetiology and Antenatal Diagnosis of Spina Bifida. South African Medical Journal, 104, 218.

[19] Chen, C.P. (2008) Syndromes, Disorders and Risk Factors Associated with Neural Tube Defects (VII). Taiwanese Journal of Obstetrics \& Gynecology, 47, 276-282. https://doi.org/10.1016/s1028-4559(08)60124-2

[20] Shehu, B.B., Ameh, E.A. and Ismail, N.J. (2000) Spina Bifida Cystica: Selective Management in Zaria, Nigeria. Annals of Tropical Paediatrics, 20, 239-242. https://doi.org/10.1080/02724936.2000.11748142

[21] Mabogunje, O.A. (1990) Spina Bifida Cystica in Northern Nigeria. Child NervSyst, 6, 103-106. https://doi.org/10.1007/BF00307931

[22] Kumar, R. and Singh, S.N. (2003) Spinal Dysraphism: Trends in Northern India. Pediatric Neurosurgery, 33, 133-145. https://doi.org/10.1159/000068819

[23] Asindi, A. and Al-Shehri, A. (2001) Neural Tube Defects in the Asir Region of Saudi Arabia. Annals of Saudi Medicine, 21, 26-29. https://doi.org/10.5144/0256-4947.2001.26

[24] Najat, F., Baradaran, N. and El Khahab, M. (2011) Large Myelomeningocele Repair. Indian Journal of Plastic Surgery, 44, 87-90.

[25] Fong, D. (2006) Spinal Dysraphism. The Hong Kong Medical Diary, 11, 7-11.

[26] Danzer, E. and Flake, A.W. (2006) Inutero Repair of Myelomeningocele. Neuroembryology and Aging, 4, 165-174. https://doi.org/10.1159/000118926

[27] Salih, M.A., Murshid, W.R. and Seidahmed, M.Z. (2014) Epidemiology, Prenatal Management, and Prevention of Neural Tube Defects. Saudi Medical Journal, 35, S15-S28. 
Submit or recommend next manuscript to SCIRP and we will provide best service for you:

Accepting pre-submission inquiries through Email, Facebook, LinkedIn, Twitter, etc. A wide selection of journals (inclusive of 9 subjects, more than 200 journals)

Providing 24-hour high-quality service

User-friendly online submission system

Fair and swift peer-review system

Efficient typesetting and proofreading procedure

Display of the result of downloads and visits, as well as the number of cited articles Maximum dissemination of your research work

Submit your manuscript at: http://papersubmission.scirp.org/

Or contact ojmn@scirp.org 